\title{
Estratégias institucionais e construções discursivas no campo do desenvolvimento local
}

Antonia de Lourdes Colbari'

\section{Resumo}

O construto desenvolvimento local é uma ideia-síntese de múltiplas dimensões reportando a um campo de poder, no qual arranjos institucionais complexos conjugam elou confrontam ações políticas e administrativas procedentes de vários atores sociais - privados e públicos. Priorizam-se, neste artigo, instituições como o Serviço Brasileiro de Apoio às Micro e Pequenas Empresas (Sebrae) e as entidades representativas dos municípios, tomadas como referências para o entendimento de dinâmicas econômicas e sociais geradas a partir das localidades. As informações extraídas de um conjunto de registros institucionais públicos (documentos e publicações) forneceram os conteúdos substantivos para os seguintes eixos analíticos: a diversidade de enquadramento conceitual do fenômeno desenvolvimento local e o sistema de crenças embutido nas construções discursivas em torno dele, garantindo-Ihe legitimidade; a normatividade dos processos de intervenção direcionados ao fomento do empreendedorismo de pequeno porte; e, por fim, os indícios de tensões, a geração de capital político e os desafios da governança no campo do desenvolvimento local.

Palavras-chave: Desenvolvimento local. Atores locais. Instituições. Pequenas empresas.

\section{Introdução}

O status do conceito de desenvolvimento, tanto na organizaçáo das relaçóes econômicas, sociais e políticas quanto na configuração das visóes de mundo, pode não lhe garantir elevada potência heurística, mas prefigura diferentes possibilidades de articulaçóes complexas entre mercado, sociedade

\footnotetext{
Doutora em Sociologia pelo Instituto Universitário de Pesquisas do Rio de Janeiro (IUPERJ), Sociedade Brasileira de Instrução (SBI) (1992), professora associada, nivel 4, da Universidade Federal do Espírito Santo (UFES), Vitória, Espírito Santo, Brasil e Bolsista de Produtividade em Pesquisa do CNPa (Conselho Nacional de Desenvolvimento Científico e Tecnológico), nivel 2. É autora de artigos publicados nas revistas: Caderno CRH (Universidade Federal da Bahia - UFBA), 2012; Cadernos EBAPE.BR (Fundação Getúlio Vargas - FGV), 2010; Sinais (UFES), 2010, entre outras. E-mail: alcolbari@terra.com.br. A autora agradece ao CNPq pela Bolsa de Produtividade em Pesquisa.
} 
e estado. O fato de reportar a um fenômeno amplo, de múltiplas faces e de grande plasticidade, tem favorecido a sua apropriaçáo por diversas teias de interesses econômicos e políticos em suas aspiraçóes hegemônicas, além de torná-lo alvo de várias interpretaçóes, instigadas por singularidades das experiências históricas de integraçáo ao sistema capitalista mundial. Assim sendo, a abordagem desse fenômeno ganha densidade teórica quando acoplada ao constructo "variedade de capitalismos", responsável pelo desenho de uma tipologia aplicada na análise da diversidade de trajetórias e de arranjos sociais, políticos e institucionais que envolvem a organizaçáo econômica capitalista (HALL; SOSKICE, 2003; AMITRANO, 2011). Essas apropriaçóes singulares produzem variaçóes discursivas e uma reciclagem conceitual periódica a respeito do desenvolvimento, como atesta o rol de adjetivos a ele acoplados: capitalista, endógeno, exógeno, autônomo, social, desigual, dependente, local, sustentável, humano, etc.

Porém, a despeito do tímido rigor conceitual do conceito de desenvolvimento, em parte decorrente de seu alargamento semântico e da diversidade de interpretaçóes que suscita, há um núcleo de significados que favorece o seu trânsito. Entre eles estáo as suas pretensóes universalistas para uma alegada inevitabilidade, um modelo geral e único de regulaçáo de conflitos sociais, depurado de "conotaçóes indesejadas", tais como os imperativos da acumulação e as diferenças de poder econômico, político e militar entre as unidades nacionais (RIBEIRO, 2008).

Historicamente presente no senso comum, na retórica política e na reflexáo acadêmica, a questáo do desenvolvimento se converteu em ponto de confluência de programas econômicos e de políticas públicas, impulsionando arranjos sociais complexos que conjugam açóes políticas e administrativas, procedentes de vários níveis do poder público (federal, estadual e municipal), e articulaçóes entre essas instâncias governamentais e os demais setores da sociedade. Uma trama social em torno de uma agenda comum tem contribuído para viabilizar modelos de "concertaçáo" pluripartite e de "consorciação", a despeito das clivagens políticas e ideológicas entre segmentos oriundos do mercado, da esfera estatal e da sociedade.

Observa-se que, a despeito de supostas tendências homogeneizantes embutidas nos projetos de desenvolvimento, sobretudo nos espaços mais globalizados, prevalecem a heterogeneidade econômica e cultural e a variedade de 
configuraçóes institucionais, inclusive no interior de uma mesma unidade nacional, geradas pela produção e reprodução de diferentes padróes de relaçóes sociais e pela força de códigos culturais singulares (MARTINELLI, 2009). Este é um aspecto substantivo no debate atual, pois as relaçóes entre cenários locais e globais e as posiçóes dos sujeitos locais suscitam novas demandas de competências técnicas e políticas, incluindo as novas "sensibilidades" para o diálogo e a negociaçáo em contextos marcados por desigualdades e diferenças. As mudanças no equilíbrio de forças favorecem a viabilidade de outro padráo de intervenção institucional por meio da formaçấo de novas redes e da presença de mecanismos de participação ampliada, em curso nas formulaçóes e na execuçáo de açôes "desenvolvimentistas" (RIBEIRO, 2008).

Neste artigo, o foco recai no desenvolvimento local, uma referência cada vez mais presente no senso comum e na literatura especializada, porém ainda impregnada de elasticidade e de imprecisáo. Interessa registrar que tal fenômeno náo se configura, obrigatoriamente, como contraponto às pretensóes universalistas e homogeneizantes associadas ao status do "desenvolvimento" na trajetória do pensamento ocidental, em geral impulsionado por grandes empresas ou pelo Estado. Em certos aspectos, pode significar um avanço nesse sentido, ao incorporar a esta matriz uma multiplicidade de dinâmicas, de agentes e de instituiçóes locais. Por sua vez, tal argumento náo autoriza uma visáo simplificadora desses processos que menospreze a força das dinâmicas fundadas em redes sociais localizadas e da multiplicidade de processos de intervenção em situaçóes de desequilíbrios socioeconômicos nos diversos territórios.

A ideia norteadora deste artigo é a concepçáo de desenvolvimento local como um campo de poder formado por grupos organizados de atores e instituiçóes, portadores de interesses e valores heterogêneos, de diferentes visóes e posiçóes políticas e em situaçóes desiguais na posse de recursos econômicos e no exercício de poder de influência e decisão. O campo permite compreender como as ordens sociais locais sáo criadas, sustentadas e transformadas (FLIGSTEIN, 2007); define-se como "uma rede de relaçóes objetivas entre posiçóes" um espaço de disputas, no qual se luta pela condiçáo de poder definir o jogo e os recursos necessários para a manutençáo do domínio sobre o jogo (BOURDIEU, 1989, 1990). Configuram-se espaços de relaçóes e inter-relaçóes marcadas por confrontos, tensões e disputas entre atores locais, 
nacionais e agências multilaterais. Porém, na contraface da competição e do conflito, estáo as possibilidades de aprendizado, os experimentos e a inovação no padrão das relaçóes (cooperação, parcerias, acordos e coalizóes) entre os diversos atores do campo, abrindo espaço para políticas públicas que, ao incorporar um tipo particular de protagonismo dos atores locais, estreitam os compromissos com perspectivas mais viáveis de promoção do bem-estar social e da cidadania (RIBEIRO, 2008; IVO, 2012). Um dos desafios decorrentes desse aporte conceitual é, justamente, entender a natureza da cooperaçáo resultante das habilidades sociais dos atores estratégicos, os quais manipulam um conjunto de mecanismos como coerçóes, sançóes, identidades e quadros culturais para a construção de coalizóes políticas que, por sua vez, dimensionam a força de cada grupo social no campo, no qual estáo em disputa os interesses de reproduçáo de arranjos estabelecidos ou de negociaçáo/imposiçáo de uma nova ordem (FLIGSTEIN, 2007).

$\mathrm{O}$ conceito de campo náo facilita a acomodação da reflexão em generalizaçóes teóricas, pois considera as possibilidades de vários projetos de desenvolvimento. Remete sempre a contextos específicos, às singularidades e pautas locais, incluindo as diversas possibilidades de arranjos econômicos, políticos e institucionais viabilizados pelos intercursos entre capital humano (os conhecimentos, as habilidades, as competências, em particular, a capacitaçáo técnica e profissional dos agentes locais), capital social (fomento das relaçóes de cooperação e confiança nos territórios, consolidando redes de conexão) e o capital físico empresarial (expansáo das bases produtivas com foco em inovação e competitividade).

O campo do desenvolvimento local é constituído por uma pluralidade de atores oriundos de diferentes segmentos de populaçóes locais e instituiçóes externas ao local; articula agentes sociais, privados e públicos, entre eles empresários, governantes de todos os níveis de governo, lideranças políticas e sociais, a burocracia pública, ONGs e movimentos sociais, entidades representativas, etc. (RIBEIRO, 2008). No presente estudo, os atores locais priorizados foram o Sebrae (Serviço Brasileiro de Apoio às Micro e Pequenas Empresas) e os governos municipais, aqui representados pela FNP (Frente Nacional de Prefeitos) ${ }^{2}$ e

2 A Frente Nacional de Prefeitos (FNP) surgiu em 1989 a partir da articulação política de um grupo de prefeitos de algumas capitais brasileiras, tendo como objetivo enfrentar os desafios emergentes da Constituição de 1988; atualmente conta com 250 municipios filiados, agrupando aproximadamente 44\% da população do pais (Disponivel em: <http://www.fnp.org.br>. Acesso em: 12 jan. 20/3.). 
pela CNM (Confederação Nacional de Municípios) ${ }^{3}$. Um conjunto de registros públicos - documentos e publicaçóes - vinculados a essas instituiçóes foi utilizado como referência discursiva exemplar para a análise das proposiçóes normativo-operativas destinadas a viabilizar políticas públicas favoráveis a uma estratégia desenvolvimentista focada nas micro e pequenas empresas (MPEs), bem como do sistema de crenças subjacentes a essas elaboraçóes diretivas. Os principais foram o Manual de Desenvolvimento dos Municipios, publicado em 2011 pela CNM em parceria com o Sebrae, e duas cartas divulgadas em 2012: a Carta dos Municípios Brasileiros pelo Desenvolvimento Sustentável e a Carta dos Municípios Brasileiros para a Rio $+20^{4}$. Em segundo plano, estiveram outros documentos, com destaque para o Guia do Candidato Empreendedor (SEBRAE, 2012) e o Documento de Conclusáo do Instituto Cidadania (2006), que sintetiza os resultados de um programa de estudos e discussóes, cujo intento era elaborar uma política nacional de fomento ao desenvolvimento local.

$\mathrm{O}$ artigo estrutura-se em quatro seçóes que sistematizam os resultados do esforço analítico-interpretativo dispensado aos registros documentais anteriormente referidos, que, em linhas gerais, constituem um abrangente material discursivo de teor informativo e prescritivo sobre as açóes e projetos institucionais, ressaltando as "regras" e as "boas práticas", além de ser uma fonte preciosa para se decifrarem os repertórios de significados compartilhados, que funcionam como uma espécie de roteiros interpretativos para a ação, mas sem excluir a interferência das habilidades sociais dos atores-chave no que tange à reproduçáo e/ou renovaçáo das ordens (campos) institucionais (FLIGSTEIN, 2007).

$\mathrm{Na}$ ordem, a exposiçáo contempla os seguintes eixos de análise: um breve esforço de desbravamento do sistema de crenças embutidos no construto desenvolvimento local; a normatividade dos processos de intervençáo direcionados ao fomento do empreendedorismo de pequeno porte; os indícios de tensáo no

3 A Confederação Nacional de Municipios (CNM), fundada durante o Encontro de Presidentes de Associações Estaduais de Municipios, realizado em 8/2/1980, tem entre seus objetivos a consolidação do movimento municipalista no Brasil, o fortalecimento da autonomia dos municípios e a reforma tributária (Disponivel em: $<$ http://www.cnm.og.br>. Acesso em: 10 fev. 2012.).

4 As duas cartas foram divulgadas em Brasilia (DF); a primeira, durante o I Encontro dos Municípios com o Desenvolvimento Sustentável, promovido pela FNP, no periodo de 27 a 29 de março de 2012 (Disponível em: <http://www.fnp.org.br>.); e a segunda, durante a XV Marcha a Brasilia em Defesa dos Municípios (16/5/20/2), tendo como lema O Poder Local na Construção de uma Nova Realidade (Disponivel em: $<$ <ttp://www.cnm.org.br>.). 
campo do desenvolvimento local; e, por fim, a geração de capital político e os desafios da governança no referido campo.

\section{O discurso do desenvolvimento local}

Escapa aos propósitos e às dimensóes desta exposição explorar historicamente o processo de construçáo do discurso em torno do desenvolvimento e do poder local. São termos controversos do ponto de vista conceitual e metodológico, pois designam genericamente um conjunto de experiências dotadas de muitos aspectos singulares, delimitadas por contextos marcados por diversidade tanto nos recursos econômicos disponíveis quanto nas crenças e nos padróes culturais e institucionais. São controversos também porque desafiam as fronteiras de uma esfera social exclusiva; pressupóem a construçáo de uma matriz conceitual e analítica, na qual os critérios de eficiência econômica náo estâo dissociados dos critérios de equidade social e do exercício da cidadania.

A concepção de desenvolvimento local não se constitui alheia às discussóes acerca do desenvolvimento em geral, incluindo o embate ideológico que posiciona, de um lado, os postulantes de modelos descentralizados de intervençáo social, sustentados pela crença na autonomia e na governança local, e, de outro, apologistas, resignados e críticos do capitalismo, porém cúmplices na ênfase nas posturas centralizadoras em torno de um ente privilegiado - o Estado nacional.

Um ponto consensual, aglutinador de diversas modalidades de crítica ao modelo de crescimento econômico centralizador, é o discurso da sustentabilidade econômica e ambiental embutido na proposta de desenvolvimento associado à promoçáo da justiça social, a despeito das divergências nutridas em torno do conceito de igualdade e das formas de combate à pobreza (SACHS, 1988, 2005; IVO, 2012). Nesse polo, observa-se a "convergência contraditória" entre as duas vertentes do desenvolvimento local (territorial) que, apesar de modeladas por referências políticas e ideológicas distintas, compartilham categorias teóricas de médio alcance de caráter polissêmico, como "governança, capital social, capital humano, redes sociais, inovação, etc." (IVO, 2012, p. 202). Em ambas, é possível rastrear empreendimentos analíticos que 
congreguem projetos coletivos e assumam posturas explicitamente normativas, insinuando os contornos de possibilidades utópicas.

A primeira edificou-se na trilha dos movimentos sociais reivindicatórios e/ou contestadores sugerindo possibilidades inovadoras de construção coletiva de experiências de índole comunitária, pautadas por lógicas econômicas e políticas descentralizadas, endógenas e orientadas por princípios de igualdade e solidariedade que legitimam a partilha da riqueza socialmente gerada e dos processos decisórios (SANTOS; RODRÍGUEZ, 2002). A segunda, de caráter liberal-normativo, articula o empreendedorismo schumpeteriano com o empoderamento e a "capacitaçáo dos pobres", os suportes da autonomia de sujeitos aptos a protagonizarem um processo de desenvolvimento local em articulação com a dinâmica nacional, embora sejam muitas as críticas de que esse arranjo virtuoso seja mais uma peça da linguagem globalizada da inclusão social (CRAIG; PORTER, 2005).

Em um meio termo, situam-se algumas vertentes neoinstitucionais, em particular a de Evans (2004), que reconhece a importância da intervençáo pública universalizada de um estado dotado de "autonomia inserida" (embedded autonomy) para o desencadeamento de dinâmicas desenvolvimentistas. Porém, não se menospreza o fato de que a complexidade das sociedades e a consequente diversidade das demandas oriundas de interesses sociais organizados tornam inevitáveis tendências descentralizadoras, pois a formulação e a implantação das políticas de desenvolvimento dependem do envolvimento dos sistemas locais de governança nesses processos.

$\mathrm{Na}$ trilha do reformismo institucional (reforma do estado e reestruturaçáo produtiva) incentivado pelo Banco Mundial, repóe-se a tese da precedência da atuaçáo eficiente das instâncias burocráticas estatais (EVANS, 1996; RAUCH; EVANS, 2000), mesmo em relaçáo ao peso de variáveis até então privilegiadas no receituário para a promoçáo do desenvolvimento, entre elas a qualidade do desempenho das instituiçóes do mercado e o combate ao excesso de intervençáo estatal. A qualidade da governança local converte-se em uma "nova categoria normativa para a ação prática" e a ideia de Estado eficiente incorpora dispositivos normativos de "bom governo" e "boas práticas", incluindo padróes morais mais rígidos e mecanismos favoráveis ao aumento 
da transparência e do controle social da gestão pública, além do fomento da cultura republicana - o antídoto contra a "herança de uma cultura política autoritária, patrimonialista, clientelista e corporativa" (IVO, 2012, p. 199).

Em outro registro, alinham-se as abordagens céticas em relação aos supostos voluntarismo e comunitarismo embutidos no "pensamento localista" cuja crença na autodeterminação da escala micro negligenciaria os determinantes macroestruturais inerentes à "lógica estrutural do funcionamento do capitalismo". Um dos alvos da crítica recai, justamente, no menosprezo dos impactos desses aspectos no conflito redistributivo e na produçáo de relaçóes assimétricas de poder, inclusive do papel do Estado nacional, relegado à condiçáo de coadjuvante diante da afirmaçáo da capacidade do local de estimular e estruturar as açóes cooperativas e de reciprocidade, bem como as reflexóes coletivas (BRANDÃO, 2007). Essa crítica ao "localismo", por sua vez, subestima a importância do entorno territorial como referência de análise, sendo o desenvolvimento local reduzido à condiçáo de estratégia de reorganizaçáo espacial do capitalismo diante da crise do modelo fordista de produçấo, portanto subordinada "à lógica do capital", ao contexto econômico globalizado que precisa se reproduzir em escala local (OLIVEIRA, 2001; VAZ; CALDAS, 2006; BRANDÁO, 2007).

Ainda sob esse enfoque analítico, retoma-se o eixo das interpretaçôes que floresceram na década de 1950, nas quais as determinaçôes estruturais, o papel estratégico do Estado e as políticas públicas em escala nacional definiam os limites e as possibilidades das iniciativas locais, justificando-se o enquadramento da "temática territorial e urbana" nos limites da "economia política do desenvolvimento" (BRANDÃO, 2007, p. 29).

A análise dos documentos institucionais que constituem a base empírica desta reflexáo explicita o tributo a um tipo de abordagem do desenvolvimento local, cuja referência bibliográfica privilegiada, embora nem sempre explícita, é Albuquerque (2004). Em síntese, as construçôes discursivas estấo ancoradas nos elementos básicos das iniciativas de desenvolvimento econômico local, tais como identificados e encadeados no discurso a seguir:

Se resalta, en primer lugar, la importancia de la movilización y participación de los actores locales. Esto supone la construcción de capital social comunitario que, a su vez, requiere el fomento de la cultura proactiva y emprendedora, alejada de la lógica 
dependiente del subsidio. Al mismo tiempo, una iniciativa de desarrollo econômico local requiere una actitud proactiva por parte de los gobiernos locales (y regionales en general) en relación con el desarrollo productivo y la generación de empleo. Esto supone asumir nuevas funciones desde la gestión pública local más allá de los roles tradicionales como suministradores de servicios sociales, urbanísticos o ambientales a nivel local. (ALBUQUERQUE, 2004, p. 163).

A natureza territorial do desenvolvimento econômico, até entấo marginalizada teoricamente, teria recuperado o seu status no entendimento das dinâmicas econômicas e sociais. Também como categoria analítica imprecisa e elástica, o território associado à concepçáo de desenvolvimento local constituirá uma chave teórica que, segundo Abramovay (2006), adquirira visibilidade a partir do início dos anos de 1980, sob inspiração da "literatura neo-marshalliana", na qual se destacava a importância do capital social gerado pelos "laços diretos entre atores sociais" (cooperaçáo e partilha de conhecimentos e de experiências) para a constituiçáo de sistemas produtivos localizados. Mais do que um modelo de industrializaçáo pós-fordista contraposto àquele centrado na grande empresa, o desenvolvimento local destaca de forma singular os valores territoriais, os elementos identitários, a diversidade e a flexibilidade (ALBUQUERQUE, 2004).

$\mathrm{Na}$ agenda pública brasileira, a abordagem territorial do desenvolvimento ganhou projeção em meados dos anos de 1990, inspirada pelas inflexóes econômicas e políticos-institucionais, em curso desde a década anterior, sob o impacto do imperativo da competitividade/reestruturaçáo produtiva, das crises sociais, do ajuste fiscal e dos apelos de uma gestáo mais democrática das questôes coletivas. Alimentam essas controvérsias em torno da associaçáo entre desenvolvimento e território a pluralidade de experiências localizadas que abrangem diversas modalidades de arranjos produtivos, novos padróes de participaçáo e a formaçáo de redes sociopolíticas.

Quanto à expressâo "local", rechaça-se a sua reduçáo a um recorte administrativo, pois ela não se confunde com o municipal: em alguns casos, pode abranger uma regiáo inteira, um conjunto de municípios. Sua referência não é o tamanho, pois "abarca o conjunto de relaçóes que existem em um determinado território", os atores sociais e a "institucionalidade da localidade com sua diversidade e potencialidades econômicas, sociais, ambientais" (MARTINS et al., 2010, p. 561); o local seria "uma substância viva, uma série de relaçōes vitais, de articulaçóes de sentido", e essas "redes dotadas de sentido" estâo "disponíveis para sinergia” (NEGRI, 1999, p. 69). 
No entanto, o emprego impreciso da palavra local frequentemente sinaliza uma ordenaçáa hierarquizada de espaços, produzida por processos socioeconômicos, que situa o micro em uma relaçáo de subordinaçáo ao macro, ambos tomados como universos separados, ou então como a esfera abaixo do regional, nacional e global. Seria "lugar", para Spink (2001, p. 11, 17), a palavra mais adequada para designar o cruzamento de vários espaços socialmente construídos: o propriamente local, o regional, o nacional e o global, tornando mais visíveis as "contradiçôes da globalização"; o "lugar" situa-se no nível meso, distante, portanto, da reificaçáo do esquema micro e macro; é "um horizonte de ligaçóes, de produçáo de sentido e de lutas" [...]; "um complexo de ligaçóes e relaçóes de colaboraçáo, solidariedade, contradiçáo, disputa e de conflito".

Os enunciados em torno do "local" antecipam a miríade de significações que nutrem a ideia de desenvolvimento no discurso das instituiçóes incorporadas nesta análise: um construto que não despreza as dinâmicas estritamente econômicas, porém as articula a uma matriz de interesses e valores mais abrangente; além das atividades e transaçóes de caráter econômico, envolve a rotina das interaçóes, a conformação das estruturas e a produçáo de sentidos que gera a identificaçáo do sujeito com o espaço ocupado (ALBAGLI, 2004). $\mathrm{O}$ construto desenvolvimento local envolve a articulaçáo sistêmica e coerente entre múltiplos fatores, não sendo recorte menor ou uma derivação automática das dinâmicas nacionais no âmbito das localidades, pois sua característica marcante é o protagonismo dos atores locais na formulaçáo de estratégias, nas decisóes econômicas e na sua execuçáo. Como um campo, ele implica em relaçóes e inter-relaçóes fundadas em valores e práticas contextualizadas, envolvidas em um sistema de crença, no qual se destacam algumas ideias estruturadoras: empreendedorismo local; capital social (cooperaçáo); território; protagonismo das cidades e gestáo compartilhada, portanto dependente de um arranjo político-institucional que favoreça a ação articulada e cooperativa entre Estado, mercado e sociedade civil.

Por fim, a retórica do desenvolvimento local, ao significá-lo como uma "dinâmica cultural e política que transforma a vida social" (INSTITUTO CIDADANIA, 2006, p. 10), sinaliza a reciclagem conceitual acerca do fenômeno do desenvolvimento. Observa-se a convergência de diversos atores na afirmaçáo de uma concepçáo de desenvolvimento que, depurada da retórica 
economicista do passado e do confinamento ao imperativo da acumulaçáo concentrada de capital, do "fundamentalismo do capital" (EVANS, 2003), é mediada por uma matriz discursiva, na qual se expressa a integraçáo dinâmica entre várias dimensóes (espaciais, econômicas, sociais, culturais e políticas): a busca da eficiência econômica está associada à mobilizaçáo do capital social, fundamental para otimizar o capital físico-econômico e o capital humano (COLEMAN, 1990), à inclusão social e à elevaçáo e adensamento do grau de participação da população nos processos decisórios. Uma pauta comum elenca os seguintes objetivos e resultados: crescimento econômico, geraçáo de emprego e renda, elevaçáo da qualidade de vida, descentralizaçáo dos investimentos públicos e o aproveitamento das potencialidades regionais, diminuição das desigualdades sociais e regionais e expansão dos negócios (SACHS, 2005).

A consistência das dimensôes técnico-econômicas e a própria lógica do desenvolvimento estáo articuladas aos espaços microssociais, tais como as cidades, concebidas estas como territórios de iniciativas econômicas, sociabilidades, aprendizagem e difusão de conhecimento (COMPANS, 2005; COMIN; FREIRE, 2009) e como ponto de confluência das açóes de vários atores: administraçáo pública, agentes econômicos públicos e privados, organizaçóes sociais e cívicas, intelectuais e opinião pública (CASTELLS; BORJA, 1996). Náo é menos importante a constataçáo de Garcia (2009) de que se a produção fordista ocorria nas fábricas constituídas como espaços privados apartados das realidades locais, a produçáo flexível tende a ser um fenômeno das cidades, transferindo para o espaço público as relaçóes sociais desencadeadas pela atividade produtiva.

\section{Os municípios e a Lei Geral da micro e pequena empresa (MPE): a normatividade operativa}

Não se pretende, aqui, inventariar as principais alteraçóes ocorridas no marco institucional, na agenda e nos instrumentos de políticas públicas direcionados às MPEs, apesar da expressiva defesa do pequeno empreendimento na arena política brasileira. Um momento exemplar desse fenômeno foi o intenso movimento que mobilizou vários segmentos sociais e culminou com a aprovaçáo, em 2006, de um novo marco regulatório para o pequeno negócio - o Estatuto da Microempresa e da Empresa de Pequeno Porte, popularizado como Lei Geral (BRASIL, 2007, 2009). Porém, sua aplicaçáo depende de 
regulamentação pelas prefeituras, a quem cabe aplicar as normas de tratamento diferenciado, cuja principal marca é assegurar tratamento diferenciado e favorecido às micro e pequenas empresas nos procedimentos de formalizaçáo da empresa, nos aspectos tributários, no acesso ao crédito e à inovação e nas aquisiçōes públicas de bens e serviços (CNM; SEBRAE, 2011).

O Manual de Desenvolvimento dos Municípios é um instrumento de mobilizaçáo de dirigentes locais para a municipalizaçáo da Lei Geral. Trata-se de um texto de orientaçáo para as açóes dos gestores públicos, no qual a apresentação de conteúdos normativos e a descrição de procedimentos operacionais não aparecem dissociadas de comentários analíticos e valorativos - um quadro de referência para a açáo, desenhado por "empreendedores institucionais" (DIMAGGIO, 1988; FLIGSTEIN, 2007), como a CNM e o Sebrae.

Uma abordagem descritiva desses conteúdos destaca, em linhas gerais, as referências frequentes às experiências bem sucedidas de desenvolvimento local em outros países e a cobertura institucional da Constituiçáo Brasileira e da Lei Geral, ambas inspiradoras de um receituário para alavancar, nos municípios, "um ciclo virtuoso de prosperidade" que, no “ideário municipalista”, envolve: fortalecer a economia incentivando o empreendedorismo local; gerar emprego e melhorar a distribuição de renda; aumentar a arrecadaçáo; e formular políticas visando à sustentabilidade econômica, social e ambiental no município, à erradicação da miséria e à elevação da qualidade de vida da população. Nessa dinâmica econômica local, o foco nas micro e pequenas empresas, além de contribuir para a estabilidade financeira e a valorizaçáo da cultura dos municípios, reduziria a sua dependência em relação à atração de médias e grandes empresas por meio de incentivos e minimizaria o êxodo de vocaçóes empreendedoras para outras cidades (CNM; SEBRAE, 2011).

Reiterando-se uma tendência geral, tal como apontada por vários autores, entre eles, Granovetter (1984), esses argumentos tornam-se ainda mais sólidos quando acompanhados dos números sobre o desempenho das MPEs no Brasil: em 2010, eram 6,1 milhóes de estabelecimentos (99\% do número total de empresas do país); geraram 14,7 milhóes de empregos com carteira assinada (51,6\% dos empregos formais privados não agrícolas); e totalizavam 40\% da massa salarial (SEBRAE; DIEESE, 2011, p. 19). Esses dados não deixam dúvidas quanto à importância do segmento para as economias locais e inspiram a construção de uma agenda pública e privada convergente em duas linhas de 
ação: a promoção do pequeno empreendimento e o desenvolvimento local. Por outro lado, cabe mencionar a instabilidade que abate essas empresas, sobre a qual os dados também sáo eloquentes: de um total de 464.700 empresas que iniciaram suas atividades em 2007, 76,1\% continuavam no mercado em 2008; 61,3\% sobreviveram até 2009; e, em 2010, apenas 51,8\% ainda estavam em funcionamento (IBGE, 2012).

Diante desse quadro, justifica-se a importância da regulamentaçáo municipal da Lei Geral, sendo ela um instrumento adequado à reduçáo da informalidade cujos efeitos negativos se manifestam na desorganização da economia, diminuição de arrecadação e comprometimento das políticas públicas destinadas ao segmento empresarial. Com o intento de facilitar a operacionalidade da regulamentação municipal da lei, o Manual apresenta a Minuta Comentada da Lei Geral, da qual alguns enunciados merecem tratamento mais apurado, pois, além de uma dimensão prescritiva, a sugestáo de instrumentos para a atuação da administração municipal explicita os contornos de uma concepçáo de desenvolvimento vinculada às potencialidades e necessidades das realidades locais e aos mecanismos de capacitaçáo social e de protagonismo local. Alguns desses aspectos sáo:

1. O fortalecimento do associativismo, estimulando-se formas cooperativas de organizaçáo social, econômica e cultural, incluindo as cooperativas de trabalho; e incentivo à formaçáo de arranjos produtivos locais que, por sua vez, favorecem a interação, cooperação e aprendizagem entre as micro e pequenas empresas integrantes de uma mesma cadeia produtiva. Se esse é um ponto vulnerável dos pequenos empreendimentos, a intervençáo estratégica das agências públicas seria providencial para a criaçáo de estruturas de governança e de articulaçáo capazes de integrar as empresas de pequeno porte facilitando a obtenção de "eficiência coletiva" (SCHMITZ, 1997).

2. O incentivo à educaçáo e à cultura empreendedora, associado ao fomento da inovaçáo, sobretudo a inovação tecnológica de caráter estratégico, por meio de isençóes de tributos; criação de fundos municipais de fomento à inovaçáo nas MPEs; e estímulo às incubadoras e aos parques tecnológicos.

3. A designaçáo de agentes de desenvolvimento, uma competência atribuída aos prefeitos pela Lei Geral, com vistas a "inserir no cotidiano dos municípios os benefícios da legislação". Seriam os agentes "servidores para 
cuidar do desenvolvimento" (SEBRAE, 2012, p. 18), cujas funçóes incluem: contribuir na identificação das potencialidades locais e das possibilidades de desenvolvê-las; implantar as açóes integradas para o desenvolvimento do município; e articular as demandas dos agentes produtivos e as entidades coletivas (sindicatos, empresas, entidades de classes, cooperativas, comitês, instituiçóes de ensino e pesquisa, etc.). Sujeitos a processos específicos de capacitaçáo, esses agentes devem articular os protagonistas das estratégias de desenvolvimento local e os atores-alvo das açóes e programas, no intuito de favorecer a complementaridade de açóes entre o poder público e o privado, potencializar as sinergias locais que incrementem a produçáo das diversas modalidades de capital, sobretudo as intangíveis, como o capital humano e o capital social.

As consideraçóes tecidas sobre aspectos selecionados da Minuta da Lei Municipal reforçam os fundamentos que sustentam as abordagens do "desenvolvimento local", no debate acadêmico e político, nas quais uma formulação intelectual complexa extrapola as demarcaçóes impostas pela lógica econômica, mas não a exclui. A compreensão das singularidades do local em um universo global envolve as variáveis associadas ao cálculo econômico e político, mas também aquelas derivadas dos códigos culturais, pois mesmo as estratégias por natureza calculistas, como aquelas em torno do capital empresarial, não se afirmam alheias à dimensão cultural. Os esforços analíticos, nesse sentido, estão permanentemente desafiados por uma multiplicidade de lógicas de ação, nas quais os interesses materiais ("enfoque de cálculo") náo estáo dissociados de outras motivaçóes menos impregnadas pela posse de bens e riquezas, justamente porque provenientes de outras matrizes, tais como a moral, os sentimentos, os laços sociais e as identificaçóes no plano do simbólico ("enfoque cultural") (HALL; TAYLOR, 1996). São as referências morais e simbólicas que fornecem o repertório de significado para a interpretação das situaçóes e definem as dimensóes rotineiras do comportamento, as quais não se movem apenas em direçáo à utilidade, instigadas pelo cálculo puramente utilitário.

\section{Espaços de tensão no campo do desenvolvimento}

Se o Manual é um documento de teor propositivo e analítico, o das cartas analisadas é político, de denúncia e reivindicação. $\mathrm{O}$ fato de serem elas produzidas em momentos de mobilizaçáo das bases das entidades representativas 
dos municípios explicita os pontos de tensão no campo do desenvolvimento, com destaque para as relaçóes entre autoridades municipais e governo federal.

A Carta dos Municipios Brasileiros pelo Desenvolvimento Sustentável demarcou as reivindicaçóes de se garantir a proatividade dos municípios na formulaçáo e na execuçáo das políticas públicas de impactos diretos no cotidiano das cidades; o status do "município como ente federado" dotado de autonomia político-administrativa, nos termos da Carta de 1988; e o "protagonismo das autoridades locais nos processos decisórios".

A Carta dos Municipios Brasileiros para a Rio+20, dirigida às autoridades, à comunidade internacional e aos participantes da Conferência das Naçóes Unidas sobre Desenvolvimento Sustentável (Rio+20), reafirmou os princípios da Agenda 21 que delinearam o caminho para um marco regulatório, no qual os municípios sáo peças importantes para a implantaçáo de "uma política global, com reflexos locais de desenvolvimento sustentado e verde, envolvendo as áreas ambiental, social e econômica", descentralização político-administrativa e a autonomia dos gestores locais.

Interessa ressaltar, nesses conteúdos, uma postura articuladora de duas tendências do desenvolvimento, uma vez que o "movimento" dos municípios assume o desafio de promover o desenvolvimento sustentável local, voltado para o fortalecimento dos micro e pequenos empreendimentos urbanos ou rurais, porém náo negligencia a importância da contribuição das empresas de grande porte. Também se reconhece a tendência inexorável de mobilidade das populaçôes para as áreas urbanas, fator a ser considerado na definiçáo de novos paradigmas de inclusáo e sustentabilidade. Não é demasiado lembrar o impacto das grandes corporaçóes globalizadas no padráo de desenvolvimento regional, nas relaçóes de emprego e de trabalho, na constituição de redes sociopolíticas e na difusão de processos de aprendizagem tecnológica e organizacional, gerando-se novas dinâmicas sociais nas esferas locais, em geral também acompanhadas pelo incremento de micro e pequenas empresas.

Em linhas gerais, os conteúdos das Cartas podem ser agrupados em dois eixos de discussão: o eixo diretivo-propositivo (proposta de um plano de ação aos municípios) e o eixo reivindicativo (demandas ao governo federal).

No primeiro eixo, alinham-se as proposiçóes também presentes no $\mathrm{Ma}$ nual, destacando-se aquelas voltadas à inclusão produtiva, como a capacitação 
profissional e técnica para o emprego e para o empreendedorismo; à melhoria do acesso aos serviços públicos; e à constituição de um ambiente adequado para o desenvolvimento local sustentável, incluindo-se aqui a organizaçáo do espaço urbano, os investimentos em segurança sanitária e em tecnologias de baixo impacto ambiental, os mecanismos de acesso ao crédito e os incentivos às atividades no terreno da economia solidária, da economia criativa e da "economia verde".

No segundo eixo, ao teor propositivo sobrepóe-se o crítico-reivindicativo, e o discurso tem como alvo o governo federal, a quem cabe garantir aos municípios o suporte financeiro para os investimentos em infraestrutura e para a erradicação da pobreza, minimizando-se as desigualdades regionais. A revisáo dos mecanismos de financiamento da açáo pública, sobretudo a garantia de repasses diretos de recursos, à revelia de convênios, mediante transferências do Fundo Nacional para os Fundos Locais, é apontada como imprescindível ao fortalecimento dos municípios como local privilegiado da promoção do serviço público direto ao cidadão.

O entendimento sobre esse conjunto de reivindicaçóes remete à Constituiçáo de 1988, que sacramentou o aumento das obrigaçóes (e despesas) do poder público municipal, pois a ele transferiu as açóes de atendimento da população, sobretudo nas áreas de saúde, educação e segurança, bem como a elevação da participação dos governos municipais na divisão dos recursos tributários. Também garantiu aos municípios o direito de firmar convênios com outros municípios, estados, agências internacionais e cidades em países estrangeiros ${ }^{5}$.

Os impactos da nova ordenação jurídica desencadearam o fortalecimento dos movimentos e das entidades de representação dos gestores municipais e instalaram focos de tensão nos aspectos operacionais da gestão municipal. As garantias constitucionais de transferência de recursos náo seriam suficientes para bancar a ampliação das despesas, situação agravada nos municípios caracterizados por alta densidade populacional, baixa capacidade econômico-financeira e elevada vulnerabilidade socioeconômica, alimentando-se o debate

5 Outros fatos importantes no desenho de uma perspectiva municipalista foram: em 200l, entrou em vigor o Estatuto das Cidades, previsto na Constituição de 1988, tendo em vista a regulação do desenvolvimento e o planejamento das cidades; e, em 2003, foi criado o Ministério das Cidades. 
em torno da necessidade de se revisar o pacto federativo, o acordo constitucional firmado entre os entes da Federação (municípios, estados e União), demarcando os limites de autonomia, prerrogativas, recursos e responsabilidades de cada um no exercício das funçóes de Estado, tendo em vista a sintonia entre as competências municipais e a transferência de recursos.

Este seria o caminho proposto para a mudança no modelo de gestão pública cujos processos são considerados excessivamente burocratizados, autônomos frente aos órgáos políticos dos poderes Executivo e do Legislativo, refratários aos mecanismos de controle social, além de pouco flexíveis e pouco sensíveis às particularidades locais, o que cria obstáculos à agilidade na açáo pública e à atraçáo de investimentos.

A dependência financeira dos municípios de recursos federais repassados por meio de convênios e por intermediação (barganha) política, com nenhuma ou baixa participaçáo da sociedade local na definiçáo de prioridades, faz deles meros executores das políticas públicas do governo federal. Configura-se uma organização institucional mais próxima da "desconcentraçáo", da "prefeiturização" do que de uma efetiva municipalização. Por essa razáo, reivindica-se a instauraçáo de um novo pacto federativo ("federalismo municipalista") em que a distribuiçáo dos recursos orçamentários seja acompanhada por avanços na "democracia administrativa", promovendo-se a "conciliação entre espaço público institucional e uma cidadania governante" por meio de procedimentos mais desburocratizados e participativos de gestão pública. Mecanismos efetivos de controle social das políticas públicas atuariam como salvaguardas da autonomia local contras as tendências de formaçáo de "feudos político-administrativos de natureza oligárquica” (HERMANY, 2012).

\section{Capital político e governança no campo do desenvolvimento local}

As estratégias de desenvolvimento local náo se configuram divorciadas de estratégias políticas destinadas a elevar o capital político dos dirigentes municipais. O compromisso com a formaçáo de "entornos territoriales innovadores para el fomento productivo y el desarrollo del tejido local de empresas" (ALBUQUERQUE, 2004, p. 164) produz aproximação e estreitamento das relaçóes com lideranças e organizaçōes representativas dos empresários. Por 
sua vez, a prosperidade econômica e melhoria da qualidade de vida produzem o reconhecimento da população e o gestor público "melhora sua imagem junto à populaçáo e se fortalece como o responsável por proporcionar um ambiente favorável para o desenvolvimento do Município" (CNM; SEBRAE, 2011, p. 17).

São alvissareiras as perspectivas de obtenção de dividendos políticos, mas a gestáo do desenvolvimento impóe novos desafios aos dirigentes locais. Segundo o Manual, a "releitura do desenvolvimentismo brasileiro", a partir de 2000, teria elevado o status das cidades, agora diante de possibilidades mais amplas e mais complexas, aumentando-se as exigências de capacitação, dedicação e compreensáo das relaçóes entre o local e o global (CNM; SEBRAE, 2011). Demanda-se uma nova estrutura de governo e de governança flexível, capaz de se adaptar às mudanças sociais em curso e de atuar em um sistema de múltiplos atores articulados: poder público (federal, estadual e municipal), empresas e organizaçóes da "sociedade civil", que podem atuar em escalas local, regional, subnacional, nacional e supranacional. A governança eficiente seria aquela capaz de garantir aos territórios a capacidade de se mover em ambientes de maior complexidade, incerteza e risco, em grande medida potencializados pela "natureza" do sistema econômico mais internacionalizado, mais competitivo e mais dependente do conhecimento.

A gestão estratégica do desenvolvimento não seria um processo de cúpula, centrado apenas nos processos macroeconômicos e macrossociais; ao contrário, ela é descentralizada e alavancada a partir de iniciativas econômicas locais voltadas para a inovação e a competitividade. A prioridade de uma abordagem territorial do desenvolvimento (cooperaçáo descentralizada entre diferentes níveis do governo e horizontal entre organizaçóes públicas e privadas) não descartaria, no entanto, a abordagem tradicional (decisóes centralizadas em torno de grandes projetos industriais em setores-chave da economia, como eixos das cadeias produtivas). A combinaçáo de ambas poderia desencadear uma "ação sistêmica de desenvolvimento local e regional" favorável a vários níveis de eficiência. E, nesse aspecto, as pretensóes analíticas do Manual semeiam ambiguidades, sugerindo o fortalecimento da pequena empresa na ótica instrumental, como escala para outro patamar de desenvolvimento, tendo como horizonte a média e a grande empresa. Afirma-se que "uma cidade ou regiáo pode e deve começar a melhorar suas instituiçóes e atratividade através 
de açóes 'bottom-up', mas quando se tornasse mais competitiva, organizada e atrativa, também tenderia a se tornar mais propensa a receber investimentos de médio e grande porte" (CNM; SEBRAE, 2011, p. 76). Uma contradiçáo com o enunciado, repetido em várias passagens do texto, de que o desenvolvimento local se caracteriza por dinâmicas específicas, tal qual o modelo embutido na Lei Geral das Micro e Pequenas Empresas, embora náo se configure alheio aos processos globalizados, embute em sua formulaçáo a valorizaçáo do pequeno empreendimento (inclusive o informal), do capital social, da inovação e do protagonismo dos agentes locais, no terreno econômico e político, isto aliado à maior autonomia e capacidade de organizaçáo dos municípios e estados.

E, nessa trilha, o sucesso de arranjos de múltiplos parceiros se vincula à eficácia da açẫo governativa e das habilidades políticas dos dirigentes locais que extrapolam as funçóes tradicionais do governo municipal e acionam qualificaçóes específicas para a afirmação de uma liderança capaz de mobilização/ agregação/compartilhamento dos diversos segmentos sociais, portanto hábil em intermediar conflitos, facilitar as coalizóes de interesses e a construçáo de consensos públicos em torno de prioridades e das iniciativas necessárias para a sua realizaçáo (COMPANS, 2005). Não menos importante seria a capacidade gerencial, incluindo a modernização da máquina administrativa, a consolidaçáo de projetos e a abertura para conviver com as parcerias e formas participativas nas decisóes públicas e no controle social delas (FISHER, 2002; ALBUQUERQUE, 2004). Um percurso que envolve empreendedorismo privado, mas principalmente o público e o associativo (ABRAMOVAY, 2006), ou o ativismo político que mobiliza o capital social (EVANS, 1996).

Retomando-se a questáo da governança do desenvolvimento, as reivindicaçóes e as propostas sublinhadas, em particular nas Cartas, sinalizam o reconhecimento de que o protagonismo econômico e político das cidades situam-se em uma configuraçáo na qual o poder público municipal depende, nos termos de Evans (2004, 2007), de densas redes de alianças, cuja formação é favorecida pelo hibridismo institucional. Além da constituição de redes empresariais - a presença dos interesses e das instituiçóes do mercado -, a governança do desenvolvimento reporta a "um espaço estratégico de intermediação e ação concertada de interesses contraditórios entre os diversos atores da sociedade civil, do mercado e do Estado, através de conselhos, comissóes e fóruns" (IVO, 2012, p. 199). 
O pressuposto das parcerias, em tese, tenderia a sedimentar relaçóes mais contratuais do que hierárquicas, acionando a dimensão "facilitadora" do poder municipal em detrimento da condiçáo de motor do desenvolvimento. As elites dirigentes locais podem atuar facilitando a percepçáo das oportunidades de investimento e sua transformaçáo em açôes efetivas (HIRSCHMAN, 1977 apud EVANS, 2004). Podem assumir "papéis desenvolvimentistas" ao produzirem "climas favoráveis aos negócios e outras qualidades especiais" (HARVEY, 1992, p. 266), uma tarefa que, segundo o mencionado autor, depende menos dos suportes em termos de infraestrutura e serviços urbanos e mais de estratégias sociais e políticas, entre elas o controle da máo de obra local (incluindo a sua qualificação), a política fiscal, a regulamentação das atividades econômicas e o estímulo seletivo das iniciativas dos empresários.

Nesse eixo da aproximaçáo dos dirigentes municipais com os demais atores envolvidos, pressupóe-se a renovação dos padróes de relação entre Estado, mercado e sociedade tendo em vista o fortalecimento do eixo democrático-participativo, necessário para a geração de consensos normativos (EVANS, 2007). Essa engenharia, por sua vez, inclui a valorizaçáo de iniciativas capazes de promover o aumento das capacidades individuais e coletivas, o exercício da liberdade, o aprimoramento da democracia (SEN, 2000) e o fortalecimento dos mecanismos de governança local, descentralizaçáo, participaçáo e elevaçáo do capital social (CASTELLS; BORJA, 1996; MILANI, 2004). Entendê-la, por outro lado, demanda um arsenal de categorias econômicas e sociológicas para explicar processos em que as potencialidades, vocaçóes, oportunidades, vantagens comparativas e competitivas aparecem associadas aos fenômenos da participaçáo, da cooperaçáo e da confiança. Trata-se de processos que simultaneamente acionam a identificação/reconhecimento/valorização dos "ativos" materiais e simbólicos pertencentes às localidades e também a afirmaçáo de identidades socioculturais.

\section{Comentários finais}

Para finalizar a exposiçáo, cabe retomar aspectos da análise mais instigantes para outras reflexóes. O primeiro reporta à acepção do desenvolvimento como uma ideia-síntese de múltiplas dimensôes da produçáo e reprodução social, resultantes de uma "conspiração multidimensional" favorável (HIRSCHMAN apud EVANS, 2004, p. 32) capaz de acionar "coalizóes 
desenvolvimentistas" nos territórios. Esse processo não subestima a importância do capital empresarial, dos interesses materiais, porém contextualiza a dimensáo econômica em estruturas institucionais concretas (NEE, 2005) em uma rede de relaçóes sociais e políticas e em referências simbólico-culturais que modelam a diversidade de interesses. Essas referências constituem as "cosmologias e idiomas de desenvolvimento" (RIBEIRO, 2008), cujas matrizes mais recentes inserem o mercado em molduras políticas e culturais, exteriorizadas em uma miríade de fenômenos, cruciais nas dinâmicas socioeconômicas territoriais: o respeito às vocaçóes, aos valores e às culturas locais, o fomento de relaçóes menos hierárquicas, a distribuição mais equilibrada de poder e o empoderamento de populaçóes e instituiçóes da localidade.

Por sua vez, a visibilidade das mudanças no cenário de ideias e valores que embasam o campo do desenvolvimento local tem sido dificultada, em geral por ser este campo marcado pela sucessáo de muitas experiências que se aglutinam, desaparecem ou reaparecem sob outra designação. $\mathrm{O}$ discurso sobre o tema é forte, envolvente e consensual, mas os resultados são pontuais, desarticulados e de baixa visibilidade. Tem alimentado visóes desencantadas diante do enfraquecimento das experiências "alternativas" que associavam as dinâmicas econômicas às dimensóes territoriais e aos valores democráticos, tal como registradas na década de 1970 . Na década de 1990, essas dinâmicas reapareceram descontextualizadas do escopo do território e das propostas de intensificaçáo da democracia. Afirmar-se-iam, desde entâo, como estratégia de geraçáo de emprego e renda em contextos de perda de dinamismo econômico das regióes (VAZ; CALDAS, 2006).

O segundo aspecto a ser comentado diz respeito aos vetores da atuaçáo institucional no campo do desenvolvimento. Um deles está nas políticas públicas de capacitaçáo e de intervençáo que visam a desenvolver as competências técnico-operativas e sociais e políticas dos indivíduos e das instituiçōes. Esse é, sem dúvida, um grande desafio para gerar dinâmicas econômicas e sociais que sustentem a produçáo de riquezas, a inclusáo social e a sustentabilidade ambiental. Essas açóes de estímulo aos atores locais para o envolvimento em iniciativas empreendedoras, cooperativas e participativas podem ser beneficiadas pela presença de certas instituiçóes, como o Sebrae e as secretarias de governo, mas tais iniciativas não resultam diretamente das açôes institucionais formais, pois os atores estáo imersos em contextos de múltiplas interaçóes, tornando 
possíveis combinaçóes complexas de arranjos sociais (GRANOVETTER, 1985; MARTINELLI, 2009). Atributos individuais e sociais, trajetórias de vida, heranças culturais, as instituiçóes e as redes informais interferem nas possibilidades de interaçóes estratégicas geradas por formas inovadoras de articulação entre as estruturas institucionais e os atores.

Outro vetor aponta para o discurso das instituiçóes, sendo algumas delas convertidas em referências discursivas por excelência, haja vista o seu empenho na propagaçáo de um sistema de crenças, a defesa de posiçóes e de ideias. Nesse aspecto, é oportuno destacar o papel primordial da linguagem no processo de institucionalização, como um veículo de objetivaçáo das "experiências partilhadas", tornando-as acessíveis a todos no interior da "comunidade linguística" e as incorporando ao "acervo coletivo do conhecimento" (BERGER; LUCKMANN, 2001). O discurso se vincula às narrativas institucionais que dáo sentido aos processos ocorridos ou aos que se pretende desencadear, tornando-se o veículo de difusão de crenças e símbolos que produzem a legitimação da própria instituição.

Nessa vertente, as instituiçóes fornecem os esquemas, as classificaçóes, as categorias e os modelos cognitivos necessários à açáo, pois os atores deles dependem para "interpretar o mundo e o comportamento dos outros atores" (HALL; TAYLOR, 1996, p. 210). Os modelos institucionais e suas referências discursivas interferem nas preferências, no "raciocínio prático" dos indivíduos, bem como na constituiçáo de identidades e imagens que constroem sobre si e sobre a vida social (THÉRET, 2003). Porém, isso náo significa reduzi-los a condiçâao de meros seguidores de roteiros predefinidos decorrentes da posiçáo ocupada na estrutura social. As açóes estáo sempre inseridas em sistemas concretos de relaçóes sociais (GRANOVETTER, 1985).

A dinâmica das instituiçóes move-se por escolhas e práticas orientadas pela busca da eficiência, mas também pela reafirmaçáo do papel social desempenhado por elas, a difusáo de sua visáo de mundo e o reforço da legitimidade social diante de seu "público". Na trilha de Habermas (1984), o desempenho institucional depende tanto da açáo estratégica (relação sujeito-objeto orientada pela racionalidade dos fins e dos meios) quanto da ação comunicativa (relaçáo sujeito-sujeito orientada pelo entendimento mútuo, em busca do consenso, da validação de propósitos e da legitimidade). 
O empenho em mobilizar, convencer e legitimar as açóes institucionais leva os atores estratégicos no campo do desenvolvimento à busca de legitimaçáo comunicativa, por meio de produção de recursos discursivos e investimento na propagaçáo de suas ideias, por meio de atividades intrinsecamente coletivas que garantem a institucionalizaçáo do "debate e intercâmbio públicos" de opinióes, tais como fóruns, reuniōes, audiências, etc. (EVANS, 2003). Nesse processo, a elevação da densidade democrática das instituiçóes favorece uma articulação virtuosa entre a perseguição de interesses próprios e as formas concretas de cooperaçáo a favor da justiça social (SEN, 2000).

\section{Referências}

ABRAMOVAY, R. Para una teoría de los estúdios territoriales. In: MANZANAL, M.; NEIMAN, G.; LATTUADA, M. (Org.). Desarrollo rural: organizaciones, instituciones y territórios. Buenos Aires: Ciccus, 2006. p. 51-70.

ALBAGLI, S. Território e territorialidade. In: LAGES, V.; BRAGA, C.; MORELLI, G. (Org.). Territórios em movimento: cultura e identidade como estratégia de inserçáo competitiva. Rio de Janeiro: Relume Dumará; Brasília, DF: SEBRAE, 2004. p. 23-69.

ALBUQUERQUE, F. Desarrollo económico local y descentralización en América Latina. Revista de la CEPAL, Santiago de Chile, n. 82, p. 157-171, abr. 2004.

AMITRANO, C. R. Capitalismo, instituiçóes e desenvolvimento: uma nota sobre a abordagem de "variedades de capitalismo". In: ENCONTRO ANUAL DA ANPOCS, 35., 2011, Caxambu. Disponível em: <www.anpocs.org.br>. Acesso em: 10 ago. 2012.

BERGER, P. L.; LUCKMANN, T. A construçáo social da realidade. 20. ed. Petrópolis: Vozes, 2001. BOURDIEU, P. Coisas ditas. São Paulo: Brasiliense, 1990.

. O poder simbólico. Lisboa: Difel; Rio de Janeiro: Bertrand, 1989.

BRANDÁO, C. Território e desenvolvimento: as múltiplas escalas entre o local e o global. Campinas, SP: Ed. da UNICAMP, 2007.

BRASIL. Estatuto da microempresa e empresa de pequeno porte: Lei Complementar $\mathrm{n}^{\circ}$ 123/2006. Brasília, DF: Câmara dos Deputados/Coordenaçáo de Publicaçóes, 2007.

. Alteraçóes no estatuto da microempresa e empresa de pequeno porte: Lei Complementar no 128/2008. Brasília, DF: Câmara dos Deputados/Coordenação de Publicaçóes, 2009. 
CASTELLS, M.; BORJA, J. As cidades como atores políticos. Novos Estudos - CEBRAP, São Paulo, n. 45, p. 152-166, jul. 1996.

CNM - Confederação Nacional de Municípios. O poder local na construçáo de uma nova realidade. Brasília, DF: CNM, 2012.

CNM - Confederaçáo Nacional de Municípios; SEBRAE - Serviço Brasileiro de Apoio às Micro e Pequenas Empresas. Manual de desenvolvimento dos municípios. Brasília, DF: CNM; SEBRAE, 2011.

COLBARI, A. Agentes de desenvolvimento e agentes de inovaçáo: a integração dos pequenos empreendimentos às dinâmicas socioeconômicas locais. In: DALLA COSTA, A. et al. (Org.). Desenvolvimento e crise na América Latina: Estado, empresas e sociedade. Curitiba: Ed. CRV, 2012. p. 91-112.

COLEMAN, J. Foundations of social theory. Cambridge: Harvard University Press, 1990.

COMIN, A. A.; FREIRE, C. T. Sobre a qualidade do crescimento: atores, instituiçóes e desenvolvimento local. Novos estudos - CEBRAP, Sáo Paulo, n. 84, p. 101-125, ago. 2009.

COMPANS, R. Empreendedorismo urbano: entre o discurso e a prática. Sáo Paulo: Ed. da UNESP, 2005.

CRAIG, D.; PORTER, D. The third way and the third world: poverty reduction and social inclusion strategies in the rise of "inclusive" liberalism. Review of International Political Economy, London, v. 12, n. 2, p. 226-263, May 2005.

DIMAGGIO, P. Interest and agency in institutional theory. In: ZUCKER, E. (Org.). Institutional patterns and organizations. Cambridge: Ballinger, 1988.

EVANS, P. Além da "monocultura institucional": instituiçóes, capacidades e o desenvolvimento deliberativo. Sociologias, Porto Alegre, n. 9, p. 20-63, jan./jun., 2003.

Autonomia e parceria: Estados e transformaçáo industrial. Rio de Janeiro: Ed. da UFRJ, 2004.

Government action, social capital and development: reviewing the evidence on synergy. World Development, Amsterdam, v. 24, n. 6, p. 1119-1132, June 1996.

Instituciones y desarrollo en la era de la globalización neoliberal. Bogotá: ILSA, 2007. (Colección En Clave de Sur).

EVANS, P.; RAUCH, J. E. Bureaucracy and growth: a cross-national analysis of the effects of 
"weberian" state structures on economic growth. American Sociological Review, Washington, v. 64 , n. 5, p. 748-765, Oct. 1999.

FISCHER, T. Poderes locais, desenvolvimento e gestăo: introdução a uma agenda. In: FISCHER, T. (Org.). Gestáo do desenvolvimento e poderes locais: marcos teóricos e avaliação. Salvador: Casa da Qualidade, 2002.

FLIGSTEIN, N. Habilidade social e a teoria dos campos. RAE - Revista de Administraçáo de Empresas, Sáo Paulo, v. 47, n. 2, p. 61-80, abr./jun., 2007.

FRANÇA, C.; CALDAS, E.; VAZ, J. C. Aspectos econômicos das experiências de desenvolvimento local: um olhar sobre a articulação de atores. São Paulo: Instituto Pólis, 2004.

GARCIA, S. R. Agentes globais em contextos locais. In: GUIMARÁES, S. M. K. (Org.). Trabalho, emprego e relaçóes laborais em setores intensivos de conhecimento: Brasil, México e Canadá. Porto Alegre: Ed. da UFRGS, 2009.

GRANOVETTER, M. Small is bountiful: labor markets and establishment. American Sociological Review, Washington, v. 49, n. 3, p. 323-334, June 1984.

Economics action and social structure: the problem of embeddedness. American Journal of Sociology, Chicago, v. 91, n. 3, p. 481-510, Nov. 1985.

HABERMAS, J. The theory of communicative action: reason and rationalization of society. Boston: Beacon Press, 1984. v. 1.

HALL, P. A.; SOSKICE, D. Varieties of capitalism and institutional change: a response to three critics. Comparative European Politics, v. 1, n. 2, p. 241-250, July 2003.

HALL, P. A.; TAYLOR, R. C. Political science and the three new institutionalisms. Political Studies, Londres, v. 44, n. 5, p. 936-957, Dec. 1996.

As três versōes do neo-institucionalismo. Lua Nova, São Paulo, n. 58, p. 193-223, 2003.

HARVEY, D. A condição pós-moderna. São Paulo: Loyola, 1992.

HERMANY, R. A pauta da Confederação Nacional dos Municípios (CNM) e o federalismo municipalista: possibilidades e perspectivas de concretizaçáo do princípio da subsidiariedade. In: CNM - Confederaçáo Nacional de Municípios (Org.). O poder local na construçáo de uma nova realidade. Brasília, DF: CNM, 2012.

IBGE - Instituto Brasileiro de Geografia e Estatística. Demografia das empresas 2010. Brasília, DF: IBGE, 2012. Disponível em: <www.ibge.gov.br>. Acesso em: 27 ago. 2012. 
INSTITUTO CIDADANIA. Projeto política nacional de apoio ao desenvolvimento local: documento de conclusão. Sáo Paulo, 2006. Disponível em: <http://www.direitoacidade.org.br>. Acesso em:10 ago. 2012.

IVO, A. B. L. O paradigma do desenvolvimento: do mito fundador ao novo desenvolvimento. Caderno CRH, Salvador, v. 25, n. 65, p. 187-210, maio/ago. 2012.

MARTINELLI, A. O contexto do empreendedorismo. In: MARTES, A. C. B. (Org.). Redes e sociologia econômica. Sáo Carlos: EdUFSCAR, 2009. p. 207-237.

MARTINS, R.; VAZ, J. C.; CALDAS, E. L. A gestão do desenvolvimento local no Brasil: (des) articulação de atores, instrumentos e território. Revista de Administração Pública, Rio de Janeiro, v. 44, n. 3, p. 559-590, out. 2010.

MILANI, C. Teorias do capital social e desenvolvimento local: liçóes a partir da experiência de Pintadas (Bahia, Brasil). Organizaçóes \& Sociedade, Salvador, v. 11, p. 95-113, dez. 2004. Ediçáo especial.

NARETTO, N.; BOTELHO, M. R.; MENDONÇA, M. A trajetória das políticas públicas para pequenas e médias empresas no Brasil: do apoio individual ao apoio a empresas articuladas em arranjos produtivos locais. Planejamento e Políticas Públicas, Brasília, DF, n. 27, p. 61-115, 2004.

NEE, V. The new institutionalism in economics and sociology. In: SMELSER, N.; SWEDBERG, R. (Org.). Handbook for economic sociology. 2. ed. Princeton: Princeton University Press, 2005. p. $49-74$.

NEGRI, A. O empresário político. In: URANI, A.; COCCO, G.; GALVÃO, A. Empresários e empregos nos novos territórios produtivos: o caso da terceira Itália. Rio de Janeiro: DP\&A, 1999. p. $59-75$.

OLIVEIRA, F. Aproximaçóes ao enigma: o que quer dizer desenvolvimento local? Sáo Paulo: Instituto Pólis; PGPC/FGV-Eaesp, 2001.

RAUCH, J. E.; EVANS, P. Bureaucratic structure and bureaucratic performance in less developed countries. Journal of Public Economics, Cambridge, v. 75, n. 1, p. 49-71, Jan. 2000.

RIBEIRO, G. L. Poder, redes e ideologia no campo do desenvolvimento. Novos Estudos, São Paulo, n. 80, p. 109-125, mar. 2008.

SACHS, I. O desenvolvimento enquanto apropriação de direitos humanos. Estudos Avançados, Sáo Paulo, v. 12, n. 33, p.149-156, maio/ago. 1988.

Desenvolvimento e cultura. Desenvolvimento da Cultura. Cultura do Desenvolvimento.

Organizaçóes \& Sociedade, Salvador, v. 12, n. 33, p. 151-165, abr./jun. 2005. 
SANTOS, B. de S.; RODRÍGUEZ, C. Introdução: para ampliar o cânone da produção. In: SANTOS, B. de S. Produzir para viver: os caminhos da produçáo náo capitalista. Rio de Janeiro: Civilizaçáo Brasileira, 2002.

SCHMITZ, H. Eficiência coletiva: caminho de crescimento para a indústria de pequeno porte. Ensaios FEE, Porto Alegre, v. 18, n. 2, p. 164-200, 1997.

SEBRAE - Serviço Brasileiro de Apoio às Micro e Pequenas Empresas. Guia do candidato empreendedor 10 passos e 100 açóes: agenda de compromissos com os pequenos negócios para a geração de emprego e renda. Brasília, DF: SEBRAE, 2012. Disponível em: <www.sebrae.com.br>. Acesso em: 11 nov. 2012.

SEBRAE - Serviço Brasileiro de Apoio às Micro e Pequenas Empresas; DIEESE - Departamento Intersindical de Estatística e Estudos Socioeconômicos. Anuário do trabalho na micro e pequena empresa: 2010-2011. Brasília, DF: DIEESE, 2011. Disponível em: <www.sebrae.com.br>. Acesso em: 11 nov. 2012.

SEN, A. K. Desenvolvimento com liberdade. São Paulo: Companhia das Letras, 2000.

SPINK, P. O lugar do lugar na análise organizacional. Revista de Administraçáo Contemporânea, Curitiba, v. 5, 2001. Número especial. Disponível em: <http://www.scielo.br/scielo. php?script=sci_arttext $\&$ pid $=S 1415-65552001000500002 \& \operatorname{lng}=p t \& t \operatorname{lng}=$ pt.10.1590/S141565552001000500002>. Acesso em: 12 jul. 2012.

THÉRET, B. As instituiçóes entre as estruturas e as ações. Lua Nova, São Paulo, n. 58, p. 225-254, 2003.

VAZ, J. C.; CALDAS, E. L. Desenvolvimento local e políticas territoriais. In: ENCONTRO NACIONAL DE ADMINISTRAÇÃO PÚBLICA E GOVERNANÇA (EnAPG), 2., 2006, São Paulo. Anais... São Paulo: ANPAD, 2006.

Data de recebimento: 10.05 .2013

Data de aprovação: 15.10 .2013

\section{Institutional strategies and discursive constructions in the field of local development}

\section{Abstract}

The local development construct is an abridged, multiple-dimensional idea reporting to a field of power in which sophisticated institutional arrangements combine and/or confront political and 
administrative actions from several private as well as public social actors. Institutions emphasized in this article are Sebrae and a number of entities representing municipal governments, taken as references for understanding economic and social dynamics generated from the localities. Information drawn from a group of institutional public records (both documents and publications) provided substantive content for the following analytical categories: the diverse conceptual framework of local development phenomena and the belief system embedded in discursive constructions around it, assuring its legitimacy; the normativity of interfering processes aimed at fostering small entrepreneurship; and, finally, the evidence of tensions, the generation of political capital and governing challenges in the field of local development.

Keywords: local development; local actors; institutions; small businesses. 